\title{
Voces feministas y disidentes en el Caribe hispano
}

\author{
Feminist and dissident voices in the Spanish Caribbean
}

Lucía Orsanic $^{1}$ (iD 0000-0002-1407-1446

'Universidad Católica Argentina, Departamento de Letras, Buenos Aires, Argentina. C1107AAZ - filosof@uca.edu.ar

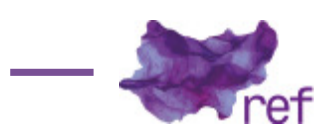

CENTENO AÑESES, Carmen.

Narradoras del Caribe hispano.

Río Piedras, Puerto Rico: Publicaciones Gaviota, 2018, 134 p.

Los aportes intelectuales de Carmen Centeno Añeses han sido muy relevantes para la inserción de Puerto Rico en el mapa de la crítica literaria. Su fluidez tanto en el campo académico como de divulgación científica queda demostrada por una serie de publicaciones en terrenos diversos, que van desde libros de carácter académico y artículos en revistas especializadas hasta trabajos de índole ensayístico, mayormente publicados en periódicos puertorriqueños y cubanos. Pese a la variedad de los temas que ha abarcado a lo largo de su vasta trayectoria, la escritura de Centeno Añeses es coherente en cuanto a sus intereses: los derechos humanos en general y los derechos de las mujeres en particular, la descolonización de Puerto Rico, la importancia del ensayo puertorriqueño en materia de independencia, el lugar de las mujeres en la tradición ensayística local, los discursos patriarcales que han dominado la historia de la literatura y la crítica literaria, la educación, entre otros temas.

Su más reciente libro, Narradoras del Caribe hispano, dialoga en cierta medida con una publicación inmediatamente anterior, Intelectuales y ensayo (2017). En este sentido, Narradoras... podría ser visto como una continuación de su labor interpretativa desde una perspectiva feminista. Si entre los intelectuales que trataba en su obra anterior, Centeno Añeses había hecho hincapié en la importancia del ensayo femenino y feminista en Puerto Rico - a través de figuras como Nilita Vientós Gascón, Áurea María Sotomayor y Marta Ponte Alsina -, ahora se adentra en el análisis narratológico de una serie de escritoras caribeñas, extendiendo el hilo feminista que las (nos) une y reúne en torno a una serie de prácticas contrahegemónicas. Y aunque no aparece explícitamente el término sororidad en las páginas de las Narradoras..., Centeno Añeses deja entrever que eso es lo que la mueve, dando lugar a una polifonía femenina pero sobre todo feminista.

Como bien señala la autora, "el auge de la escritura femenina se ha producido en las últimas décadas como fruto del interés de diversos sectores sociales y el surgimiento de variados actantes globales" (Carmen CENTENO AÑESES, 2018, p. 9). Así, las temáticas abordadas por las escritoras se han ido abriendo camino paulatinamente y ya no se limitan al mundo doméstico; sino que incursionan con paso firme en la política, en la memoria y en la historia, llevando a cabo la subversión de una tradición narratológica anclada en la dominación patriarcal. Centeno Añeses pretende romper este sesgo, con una mirada lúcida que repasa a aquellos que fueron célebres en el mundo literario, quienes fueron objeto de lectura y de análisis: son nombres masculinos y masculina es también la crítica que se ha hecho en torno a ellos. Esto no significa 
que no haya habido mujeres escribiendo a la par pero no fueron ellas quienes recibieron los metadiscursos más "relevantes y estridentes" (CENTENO AÑESES, 2018, p. 10); esto estaba reservado para el mundo de los hombres. Frente a los renombrados Alejo Carpentier, Gabriel García Márquez, Carlos Fuentes y Mario Vargas Llosa; la autora trae a las contemporáneas Ángeles Mastretta, Laura Esquivel, Isabel Allende y Ana Lydia Vega. Sienta a la mesa pesos pesados como Judith Butler y Luce Irigaray, y continúa con Cristina Rivera Garza y Rosa Beltrán. Reconoce que las escritoras caribeñas pasan desapercibidas en el canon; con excepción de nombres como Rosario Ferré, Julia Álvarez y Josefina Báez. Las latinoamericanas Gioconda Belli, Cristina Peri Rossi y Diamela Eltit mostraban deseos de desprenderse de las nociones androcéntricas, que las oprimían con la fuerza de un corset. Y en Puerto Rico, al lado de las ya mencionadas, hay que añadir las voces de Olga Nolla, Nemir Mattos Cintrón y Liliana Ramos Collado como los primeros intentos de deconstrucción narrativa del papel tradicionalmente asignado a la mujer. Asimismo, las cubanas Luisa Campuzano y Zayda Capote han hecho aportes en materia de crítica feminista, así como también destacado los nombres de sus compatriotas: Aida Bahr, Mylene Fernández Pintado, Reina María Rodríguez, Laidi Fernández, Lourdes González y Ena Lucía Portela. Finalmente, entre las narradoras dominicanas, la autora señala a Ángela Hernández, Carmen Imbert Brugal, Ligia Minaya y Rita Indiana Hernández.

A la luz de este historial, Centeno Añeses analiza el tema de la memoria y su vínculo con la literatura en textos de las puertorriqueñas Magalí García Ramis, Marta Aponte Alsina y Mayra Montero. Esta última también es estudiada por la autora a propósito de la negritud y la no occidentalidad. La escritora ruso-cubana Anna Lidia Vega y la puertorriqueña Ana María Fuster Lavin constituyen el corpus para analizar la sexualidad femenina, la violencia y la locura. La cubana Lourdes de Armas interesa por su abordaje del marxismo y la poesía, en el contexto matrimonial de la protagonista. Luego, Mayra Santos Febre es retomada por Centeno Añeses, a propósito del giro espacial, la cibercultura y el tiempo; y Yolanda Arroyo Pizarro, desde la sexualidad, la ecología y la política. Finalmente, la santería, la transexualidad y el ecologismo de Rita Indiana culminan el rosario de voces disidentes que integran las Narradoras...

De los dos párrafos anteriores se comprende que leer la obra de Centeno Añeses supone un verdadero catálogo de las voces femeninas disidentes. Exige hacer un repaso concienzudo de la historia de la literatura latinoamericana y caribeña, tomar nota de todos y cada uno de los nombres propios que aparecen relevados y leer. Antes que nada, leer. Traspasar los umbrales en los que nos ha encerrado la universidad, la academia y hasta el propio mercado editorial para conectarnos con otros relatos, con otras voces, con otras formas de narrar. Centeno Añeses se revela como una lectora voraz y consciente, voraz y crítica, voraz y contrahegemónica. La misma voracidad que durante siglos pesó en la mujer de forma negativa, y la colocó en el lugar arquetípico de la lujuria por parte de la iglesia, es ahora la que hay que recuperar. Mujeres peligrosas son las que leen, más aún las que escriben. Centeno Añeses encarna las dos: lee vorazmente para escribir con la misma voracidad. Y nos tiende el hilo para conectar a unas mujeres con otras - las que leen y las que escriben -, a fin de recuperar la hermandad femenina de otros tiempos, resguardada en los aquelarres. Encendamos otra vez el fuego. Somos muchas.

\section{Referencias}

CENTENO AÑESES, Carmen. Intelectuales y ensayo. San Juan: Publicaciones Gaviota, 2017.

CENTENO AÑESES, Carmen. Narradoras del Caribe hispano. Río Piedras, Puerto Rico: Publicaciones Gaviota, 2018.

Lucía Orsanic (luciaorsanic@yahoo.com.ar) es Doctora en Letras por la Universidad Católica Argentina, donde se desempeñó como docente e investigadora con Dedicación Especial, en las categorías Junior y Senior, para el Departamento de Letras, entre 2009-2017. Posee un Máster en Estudios Medievales Hispánicos por la Universidad Autónoma de Madrid, donde obtuvo la Beca con cargo al Fondo Social de Estudiantes de la Universidad Autónoma de Madrid. Fue becaria de la Fundación Carolina en la Escuela de Lexicografía Hispánica de la Real Academia Española, en Madrid. Ha publicado diversos artículos académicos en revistas especializadas, particularmente a propósito de la teratología y la zoología literarias; además del libro La mujerserpiente en los libros de caballerías castellanos. Forma y arquetipo de lo monstruoso femenino (Madrid, La Ergástula, 2014); y Un cuento para Irupé: El león sin melena (Buenos Aires, Casa de Gatos, 2016). Es miembro fundador y editora en Ediciones del Flamboyán (San Juan, Puerto Rico). 


\section{COMO CITAR ESSE ARTIGO DE ACORDO COM AS NORMAS DA REVISTA}

ORSANIC, Lucía. "Voces feministas y disidentes en el Caribe hispano". Revista Estudos Feministas, Florianópolis, v. 27, n. 2, e60482, 2019.

\section{CONTRIBUIÇÃO DE AUTORIA}

Não se aplica

\section{FINANCIAMENTO}

Não se aplica

\section{CONSENTIMENTO DE USO DE IMAGEM}

Não se aplica

APROVAÇÃO DE COMITÊ DE ÉTICA EM PESQUISA

Não se aplica

\section{CONFLITO DE INTERESSES}

Não se aplica

\section{LICENÇA DE USO}

Este artigo está licenciado sob a Licença Creative Commons CC-BY Internacional. Com essa licença você pode compartilhar, adaptar, criar para qualquer fim, desde que atribua a autoria da obra.

\section{HISTÓRICO}

Recebido em: 29/1 1/2018

Aprovado em: 12/02/2019

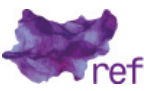

